\title{
CORRECTION
}

\section{Legalize marijuana without the smoke}

In a commentary published on Jan. 30, 2017, the author's affiliation "Centre for Addiction and Mental Health" incorrectly included the location "Ottawa, Ont." The location should have been "Toronto, Ont." This has been corrected at cmaj.ca.

- Cite as: CMAJ 2017 March 27;189:E474. doi: $10.1503 / \mathrm{cmaj} .170237$

\section{Reference}

1. Schwartz R. Legalize marijuana without the smoke. CMAJ 2017;189:E137-8. 